\title{
Quão distantes estão as metodologias emergentes centradas na geração y, em relação aos nativos efetivamente digitais. Reflexões e apontamento de soluções sob a ótica da estratégia de evolução adaptativa
}

\author{
Carlos A. V. Araújo jr, Divino R. S. Ferreira, Nayara S.C. Chiovato, \\ Luciano Vieira Lima
}

LINA, Laboratório de Inteligência Natural e Artificial, Faculdade de Engenharia Elétrica Universidade Federal de Uberlândia (UFU) - Uberlândia - MG - Brazil

carlosjrvieira14@gmail.com, divinoferreira33@yahoo.com.br, asc.nayara@gmail.com, lucianovieiralimaster@gmail.com

Abstract. It is clear that in these 12 years analyzing new students in computer engineering, that educators are with great inertia to understand that in recent years the target audience, the future generation, Y Generation, has changed. A new generation, we call for "effective digital generation" has entered in colleges by providing a vision, mission, completely different ambitions and goals of Generation Y. A generation that is not lost, as at first appears to be. Lost are those looking for rebuild them in ambitious ways that were designed for a highly technologically skilled generation, Y Generation, but multifocused, lacking goals, whys, the how, when and where.

Resumo. Observa-se, nestes 12 anos analisando alunos ingressantes em engenharia de computação, que os educadores estão com grande inércia em entender que nos últimos anos o público alvo, geração do futuro, a geração $Y$, mudou. Uma nova geração, que denominamos por "geração efetivamente digitais) tem ingressado nas faculdades trazendo uma visão, missão, ambições e metas completamente diferentes das anteriores. Uma geração que não está perdida, como aparenta, a princípio, aos educadores. Perdidos estão aqueles que procuram reconstruí-las nos moldes ambiciosos que foram idealizados para uma geração altamente capacitada tecnologicamente, a geração $Y$, mas multifocada, carentes de metas, de por quês, do como, quando e onde.

\section{Introdução}

Geração Y (a geração dos por quês? - Why Generation ou Y Genaration), a princípio denominada por nativos efetivamente digitais, uma geração multifocada (Cury, 1999), ansiosa, antenada com a tecnologia como meta para conquistar o mundo, mas fica perdida no meio de tantas opções. Uma geração de que de nativos efetivamente digitais não possuem nada, como já conceitua Prensky (2011), onde

"...nativo é quem fala com fluência e sem sotaque a linguagem, e, "imigrante" é quem veio para este território no tempo presente com heranças do passado." 
A Geração Y é uma geração imigrante na tecnologia, que, apesar de passar a dominá-la, tem fortes heranças do passado onde a mesma não existia Não nasceu com a tecnologia. Já os Nativos Efetivamente Digitais, foco dos últimos 2 anos desta pesquisa, quando adentraram nas universidades, é uma geração aparentemente sem foco, tranquila, focada no mundo digital e sem ambições no mundo físico.

Reconhecidamente pelos usuários de tecnologia mobile, o marco da geração smart de dispositivos iniciou em 2007 com o primeiro Iphone. As gerações que passaram a ter acesso à tecnologia smart, com acesso global pela internet, somente passaram a existir após o ano 2000, por usuários, na maioria, ainda não totalmente inclusos digitalmente. Os filhos desta geração, os nativos efetivamente digitais, assim denominados nesta pesquisa, somente a partir deste marco passaram a ter contínuo, progressivo, desde o nascimento tendo, já no berço, como primeira babá e recurso lúdico a tecnologia mobile. Nesta pesquisa considera-se os nativos efetivamente digitais até um gap de 4 anos antes deste marco, ou seja, 1996, estando os mesmos agora entre 16 e 20 anos, faixa do estudo nos últimos 2 anos que trouxeram um grande diferencial, sob o ponto de vista do ensino, em relação à Geração Y.

Entender algumas características fundamentais e a diferença entre a Geração Y, nativa digital [Lemos 2009], e a geração dos nativos efetivamente digitais é mais fácil por analogia:

Quando uma pessoa é pobre e fica muito rica, muitas delas passam a dar muito valor à riqueza, querem mostrar para todos que elas estão ricas, só falam de preço, de quanto custa o que adquirem, que elas podem comprar o que quiser, muitas vezes ficam arrogantes e intolerantes com quem ainda é pobre. Estes eram chamados, no século passado, pejorativamente, de novos ricos (nouveau riche, new rich ou new Money).

Quando uma pessoa nasce em berço rico, rico de nascença, onde dinheiro nunca foi problema e nem é citado. Vivem em um ambiente em que não se conversa em dinheiro, apenas se gasta, não ficam mostrando o que possuem nem quanto custou, apenas possuem, consomem e compram o que desejam sem se importar se é caro ou barato, aliás, não sabem a diferença entre caro e barato, para eles é a mesma coisa. Não compram pelo preço, compram apenas porque desejam ou precisam. São seletivos, mas gentis ao modo deles, alienados com os problemas do mundo, com as crises econômicas, não se preocupam com planos de saúde, transporte ou moradia. Para eles, problemas com dinheiro é como um filme do qual não pertencem, estão fora da realidade, não conseguem ter noção, quantificar o que significa tal problema. Só terão noção quando se encontrarem falidos sem conseguir entender que mundo é este onde o dinheiro é algo muito importante. Normalmente dizem não se importar com o dinheiro, que não precisam de dinheiro (realmente, não precisam, já possuem).

Uma vez, a equipe dessa pesquisa esta em reunião com investidores. Um deles, reconhecidamente "novo rico" disse: - .. mas para fazer o que se deseja é preciso investir cem mil reais. O outro, rico de nascença, comenta: ... OK, mas quem é que não tem cem mil reais para fazer isto? Observou-se que o que foi dito não soou como arrogância, mas como se fosse algo natural e lógico.

Esta é a diferença entre a geração $\mathrm{Y}$ e os nativos efetivamente digitais. Os nativos efetivamente digitais já nasceram digitais, a geração $\mathrm{Y}$, imigrante, teve que conquistar este espaço, o conhecimento, se adaptar às habilidades e competências na 
qual a geração de nativos efetivamente digitais já é nata. Portanto, a geração Y equivale ao "novo rico" e os nativos efetivamente digitais aos ricos de nascença.

Assim, os estudos e análises concluíram que a geração de nativos efetivamente digitais não tem crise do que vai ser, do que escolher para atingir os objetivos e atingir as mais altas aspirações. Os nativos efetivamente digitais já nasceram onde querem estar, ou seja, plugados desde bebês com os tabletes nos berços como primeira babá. Não têm aspirações de onde chegar, eles já estão lá. Não são alienados do mundo, eles estão centrados, focados no mundo que conhecem e onde vivem: no digital. Claro que a maioria, um dia, quando mais velhos, ou velhos demais, acordem e vejam que não dá para sobreviver no mundo digital apenas, para a maioria deles os bitcoins não pagarão o que se gasta no dia a dia. Os nativos efetivamente digitais só vão entender a agonia da Geração $\mathrm{Y}$ e anteriores quando tiverem que sair do mundo deles e entrar no que a geração Y chama de mundo real, o que, para os nativos efetivamente digitais, não é verdade. Neste momento é interessante lembrar o filme Avatar, um filme de ficção científica de 2009, escrito e dirigido por James Cameron. Fica claro neste filme onde o personagem principal vive plenamente e onde o mesmo padece, onde encontra a verdadeira felicidade e onde reside a angústia e a tristeza, onde se tem e onde se carece de soluções.

Portanto, tudo que a duras penas se construiu e se estruturou para informar, ensinar, para educar a geração Y, em um curso de graduação, por exemplo, teve uma vida curta já que os mesmos já obtiveram sua formação profissional e, atualmente, só se ingressa nas faculdades os nativos efetivamente digitais que praticamente caem de paraquedas em um curso através de programas como o ENEM aos 16/17 anos de idade.

A geração Y carece de terapia para solucionar os problemas existenciais, os nativos efetivamente digitais não têm problemas, vivem. Não têm crises como a geração Y e anterior. Um fato que corrobora com tal afirmação é o simples observar dos nativos efetivamente digitais durante o dia todo. Ver-se-á que estão todos plugados, conversando com se sabe quem, contando todos os detalhes da vida pessoal delas, dos pais, dos amigos, de intimidades que nem a geração $\mathrm{Y}$ consegue dizer em uma seção com um psicólogo (típico da geração Y). Antes que alguém pergunte, cada detalhe da vida do nativo digital é exposto em palavras, fotos e vídeos em várias redes sociais, sem pudor ou restrição.

A geração $\mathrm{Y}$ foi assolada pela geração de nativos efetivamente digitais, assim como o Forró e a Música Baiana foram assolados pela música sertaneja. Não existem medidas em curto prazo, daí se pensar em um processo evolutivo onde evolução não significa maior ou melhor capacitação, mas sim adaptação (frase polêmica, mas que se aplica bem a esta questão). Não há como exigir em um curto espaço de tempo de uma graduação que se consiga uma boa adaptação do aluno aos modelos antigos de ensino. Um processo de adaptação tão intrínseco que necessitaria de uma destruição completa do que se é para uma reconstrução do que se desejaria que fossem. Este é o sentimento que muitos nativos efetivamente digitais possuem ao entrar em um curso superior.

Assim, é mais rápido se adaptar ao ensino um processo evolutivo ativo complementar no mundo dos nativos efetivamente digitais do que manter um processo destrutivo/reconstrutivo quem vem sendo aplicado à geração dos nativos efetivamente digitais.

\section{2- Processo Evolutivo ativo}


Entendendo que a adaptação das metodologias de ensino à geração digital é a forma mais rápida para que não se perca a capacitação efetiva de uma ou mais gerações de graduados, surge o apontamento de uma solução evolutiva para capacitação e resgate dos nativos efetivamente digitais ao mundo físico em ações de interação e integração das habilidades e competências que os mesmos trazem de bagagem desde o nascimento, ou seja, o conhecimento e controle total da manipulação dos processos de comunicação e de ações intuitivas e efetivas no mundo digital. Esta habilidade tão desejada pelas gerações anteriores e já nata nos nativos efetivamente digitais. Este processo evolutivo não se basta nos cursos de graduação, mas pode ser aplicado já desde a tenra idade aos 4 anos de idade, como os desenvolvedores da linguagem de programação CODE (An s/d e Computer $\mathrm{s} / \mathrm{d}$ ) já estão implementando em todo o mundo, onde aproximadamente 200.000 instituições de 180 países do mundo se reuniram na mesma semana em dezembro de 2015 para uma unificação de pensamento, ações e habilidades para dotar crianças de 4 a 99 anos neste processo evolutivo(Hour s/d). Esta ação é fundamental para inclusão familiar onde a criança evolui no mundo digital amparada, acompanhada pelos familiares, como os avós ou pais que tiveram e tiverem tempo para iniciar o aprendizado juntos. O crescimento conjunto e continuado elimina a distância de gerações e integram o nativo digital ao processo familiar, promovendo o respeito e não a alienação e desrespeito que hoje imperam entre as gerações causadas pelo perfil dos nativos efetivamente digitais. Por outro lado, as gerações antigas, a família, passam também a evoluir fazendo parte do mundo dos nativos efetivamente digitais, e, assim, tentando uma coalisão entre os mundos que cada um julga ser o real e mais importante e não uma colisão (como vem acontecendo).

Outra ação é como atualmente uma equipe de pesquisa tem aplicado o conceito de evolução em disciplinas iniciais do curso, como em Introdução à Engenharia de Computação, onde o curso parte das habilidades do uso da tecnologia mobile pelos nativos efetivamente digitais e acrescentam, evolui o uso de tal tecnologia ao dotar os alunos das habilidades e competências mínimas para que, já no primeiro período o aluno consiga interagir com o mundo físico através de comandos disparados pelo celular. Assim, não há uma quebra do fluxo de atividades do nativo digital ao adentrar na faculdade, mas um processo de aprimoramento, de evolução, de complementação desejada e útil dos mesmos, integrando-os aos objetivos e metas traçados em tal curso na capacitação profissional dos mesmos, bem como na socialização com as gerações anteriores (professores, profissionais de empresas, outros).

\section{3- Avaliação de Resultados - Conclusão}

Os autores deste artigo participaram e participam ativamente nos dois eventos citados neste artigo, onde se pode acompanhar de perto que o processo evolutivo ativo participativo tanto familiar quanto dos professores em todos os graus do ensino traz resultados excelentes e esperados com tal ação. A interação e integração direta com o mundo real dos nativos efetivamente digitais trazem ganhos para todos os agentes participantes do processo, assim como para um menor distanciamento de gerações. Um ano e meio de processo de integração familiar, com crianças de 4 a 9 anos e de integração tecnológica entre as de 16-18 anos em curso de graduação surpreendem em resultados do que se almejava inicialmente. Como prova disto tem-se o caso de três nativos efetivamente digitais, iniciantes em Engenharia de Computação na FEELTUFU, os quais ingressaram no evento $2^{\circ}$ Startup Weekend Uberlândia $2016\left(2^{\circ} \mathrm{s} / \mathrm{d}\right)$, considerado pela EXAME (Uberlândia s/d) como um dos grandes eventos de startup do 
V Congresso Brasileiro de Informática na Educação (CBIE 2016)

Anais do XXII Workshop de Informática na Escola (WIE 2016)

mundo, obtendo o $2^{\circ}$ lugar de melhor projeto, o qual interagia solução mobile com o mundo real (que era o objetivo didático do curso citado).

Evolução em vez de um processo destrutivo-reconstrutivo: um processo de adaptação que realmente traz bons resultados em curto prazo.

\section{Referências:}

Cury, A. J. (1999). Inteligência Multifocal. Análise da Construção dos Pensamentos e da Formação de Pensadores. Ed. Cutrix.

Oliveira, S. (2011). Geração Y - Ser Potencial ou Ser Talento? Faça por merecer. 1 ${ }^{\mathrm{a}}$ Ed.. Editora Integrare.

Palfrey, J.; Gasser (2011), Nascidos na Era Digital: Entendendo a primeira geração de nativos efetivamente digitais. Ed. Artmed.

Lemos, S. (2009). Nativos efetivamente digitais x Aprendizagens: Um Desafio Para a Escola. B. Téc. Senac. PDF. Acesso dia 12/06/2016. Disponível em: file://C:/Users/Usu\%C3\%A1rio/Downloads/Nativos\%20digitais\%20e\%20aprendiza gem.pdf

An Hour of Code for every student. Code.org. Acessado em: 12/06/2016. Disponível em: https://hourofcode.com/br/en

------ Computer Science Fundamentals for elementar School. Code.org. Acessado em: 12/06/2016. Disponível em: https://code.org/educate/curriculum/elementary-school

Hour of Code 2015 - WORLDWIDE. YouTube.com. Acessado em 12/06/2016. Disponível em: https://www.youtube.com/watch?v=2DxWIxec6yo

$2^{\circ}$ Startup Weekend Uberlândia. Google. Acessado em: 12/06/2016. Disponível em: http://www.up.co/communities/brazil/uberlandia/startup-weekend/8539

-----Uberlândia-MG vai receber o maior evento de startup do mundo. Revista Exame.com. Acessado em: 12/06/2016. Disponível em: http://exame.abril.com.br/negocios/dino/noticias/uberlandia-mg-vai-receber-o-maiorevento-de-startups-do-mundo.shtm 